DOI 10.31509/2658-607x-2019-2-3-1-21

УДК $504.732: 504.064 .37: 528.88: 528.94$

КАРТОГРАФИРОВАНИЕ ДИНАМИКИ РАСТИТЕЛЬНОГО ПОКРОВА

ТЕРРИТОРИИ НАЦИОНАЛЬНОГО ПАРКА «КУРШСКАЯ КОСА» ПО МАТЕРИАЛАМ КОСМИЧЕСКОЙ СЪЕМКИ ALOS И SENTINEL-2

(C) 2019 г. А.Д. Никитина*, С.В. Князева, Е.А. Гаврилюк, Е.В. Тихонова, С.П. Эйдлина, Н.В. Королева

Центр по проблемам экологии и продуктивности лесов РАН

Россия, 117997, Москва, ул. Профсоюзная, 84/32, стр. 14

*E-mail: nikitina.al.dm@gmail.com

Поступила в редакцию 24.06.2019

В статье отражены результаты оценки количественных изменений площадных характеристик растительного покрова национального парка «Куршская коса», на основе материалов разновременной мультиспектральной съемки высокого пространственного разрешения со спутников Alos и Sentinel-2. Опробованы алгоритмы автоматизированной классификации «Случайный лес» (Random Forest) и максимального правдоподобия (Махіmum Likelihood Estimation). На основе результатов автоматизированного дешифрирования космических снимков рассчитаны показатели мониторинга экосистем национального парка (лесистость, доля хвойных пород в древостоях, доля развеваемых (открытых) песков и песков, покрытых растительностью (закрепленных песков)), составлены карты динамики показателей и карта разновременного состояния растительности. Картографическая оценка демонстрирует основные тренды изменения структуры растительного покрова национального парка за десятилетний период с 2007 по 2017 г.: увеличение лесистости и доли закрепленных растительностью песков со стороны Куршского залива в результате лесозащитных мероприятий, уменьшение лесистости и увеличение доли развеваемых песков со стороны морского побережья в результате разрушения авандюны под воздействием ветро-волновой и рекреационной нагрузки.

Ключевые слова: растительный покров, древостои, спутниковые данные высокого пространственного разрешения, автоматизированное дешифрирование, алгоритмы классификации, достоверность распознавания, показатели экологического мониторинга, карты динамики.

Данные дистанционного зондирования (ДДЗ) являются одним из основных источников изучения и картографирования сложной структуры растительного покрова. Космические снимки различного пространственного разрешения широко применяются в целях анализа динамики растительного покрова, инвентаризации и картографирования лесов, оценки биоразнообразия и ресурсного потенциала лесных экосистем и т. п. (Gould, 2000; Малышева и др., 2002; McRoberts et al., 2010; Nagendra et al., 2013; Turner et al., 2015; Boisvenue et al., 2016; Комарова и др., 2016). Использование ДДЗ в области инвентаризации, мониторинга и охраны растительных сообществ отражено в ряде зарубежных и отечественных обзоров (Малышева, 2002; Сухих, Жирин, 2005; Xie et al., 2008; Homolova et al., 2013; Banskota et al., 2014). 
Основные факторы, влияющие на спектральные характеристики древесных растений, соотношение пигментов, особенности внутреннего строения и общий процент влаги листьев. Наиболее информативными каналами в оптическом диапазоне съемки для изучения растительного покрова являются зеленый, красный, ближний инфракрасный (ИК). Периодичность съемки одних и тех же областей земной поверхности особенно важна для мониторинга растительного покрова, идентификации объектов или явлений на снимках и их изменений во времени. Космические мультиспектральные снимки с пространственным разрешением 10-30 м целесообразно применять для оценки состояния лесного покрова на региональном и локальном уровнях (Князева, 2006; Лабутина, Балдина, 2011; Рязанов и др. 2015; Immitzer et al., 2016). Снимки Landsat наиболее широко используются для пространственного анализа и динамики растительного покрова (Gavier-Pizarro et al., 2012; Курбанов и др., 2013; Hansen et al., 2013; Рассказов, Галаганова, 2014; Banskota et al., 2014; Chen et al., 2015; Королева и др., 2018). Для картографирования растительности наземных экосистем на региональном уровне сотрудниками ЦЭПЛ РАН разработаны методики с использованием спутниковых данных Landsat-TM/ETM+/OLI (Гаврилюк, Ершов, 2012). Мультиспектральные съемочные системы с пространственным разрешением 10 м (ALOS, SPOT, Sentinel-2, Канопус-В) оптимально использовать для картографирования лесов на локальном уровне, т.к. они обладают достаточно большим пространственным охватом и в то же время необходимой степенью детальности изображения природных объектов. Преимуществом спутниковых данных высокого разрешения является также их значительно меньшая стоимость и большая доступность по сравнению с космическими снимками сверхвысокого разрешения. Применение подобных спутниковых данных целесообразно для оценки динамики растительного покрова национального парка «Куршская коса», территория которого отличается сложной формой для картографирования и организации дистанционного мониторинга (узкая и извилистая, вытянутая по диагонали в направлении север-юг).

Национальный парк (НП) «Куршская коса» расположен в Зеленоградском районе Калининградской области РФ, площадь территории парка 66.21 км² (Официальный сайт НП «Куршская коса). НП, организованные на российской и литовской части Куршской косы, являются единым объектом всемирного культурного и природного наследия ЮНЕСКО «Куршская коса». Протяженность российской части Куршской косы составляет 48 км, ширина варьирует от 400 м до 4 км. Относительно небольшая территория парка отличается высоким ландшафтным и ценотическим разнообразием, богатым видовым составом лесных сообществ. Для Куршской косы характерна высокая динамичность природных и антропогенных воздействий, имеющих сезонные и годовые колебания. Примерно 70\% природных ландшафтов Куршской косы могут быть отнесены к категории слабоустойчивых, неустойчивых и сильно 
неустойчивых, что связано с постоянными интенсивными водно-ветровыми эрозионными и антропогенными воздействиями (Шаплыгина, Волкова, 2017). Основными лесообразующими породами являются сосна, ольха черная, береза, ель. Более 77\% лесных насаждений имеют искусственное происхождение (Чебакова, 1996). Большую часть лесопокрытой площади занимает сосна обыкновенная (около 50\%). Сосняки представлены преимущественно средневозрастными древостоями или молодняками на возвышенных формах рельефа. В прикорневой части косы на территориях с хорошим увлажнением произрастают ельники влажнотравные. На обширных пониженных участках с избыточным увлажнением (пальве) преобладают черноольховые леса. Около $25 \%$ лесопокрытой площади занято мелколиственными лесами. В березняках преобладают разнотравье и мхи, а в подлеске широко представлены малина и ежевика. Особенностью Куршской косы является наличие незакрепленных песков, на долю которых приходится около 10\% территории НП. С ХІХ века на Куршской косе ведутся работы по закреплению песков путем посадки деревьев и созданию авандюны. В настоящее время при неоправданных хозяйственных работах и рекреационных нагрузках существующее равновесие легко может быть нарушено, что повлечет негативные последствия для всех биотопов Куршской косы (Губарева, 2009). Мониторинг состояния авандюны и лесов, закрепляющих пески, является одной из первоочередных задач для сохранения ландшафтов особо охраняемой природной территории и объекта всемирного культурного и природного наследия ЮНЕСКО «Куршская коса». Таким образом, наблюдения за изменениями в пространственной структуре растительного покрова особенно актуальны, так как прибрежно-морские экосистемы полуострова находятся под постоянным интенсивным воздействием различных факторов окружающей среды, легко уязвимы и обладают высокой динамичностью.

Цель данного исследования заключается в выявлении изменений площадной структуры основных типов растительности НП «Куршская коса» под воздействием абиотических, биотических и антропогенных факторов за период 2007-2017 гг. на основе разновременных мультиспектральных спутниковых данных высокого пространственного разрешения Alos и Sentinel-2.

\section{МАТЕРИАЛЫ И МЕТОДЫ}

Для задач изучения динамики растительного покрова часто используется метод создания мультивременных композитов из серии снимков, полученных для одной территории в разное время (Тютрин, Кондратовец, 2010; Ялдыгина, 2011; Hansen et al., 2013; Гранкина, Мишвелов, 2014; Banskota et al., 2014). Однако такой метод подходит только для космических снимков, полученных при одинаковых условиях съемки одной аппаратурой. Погрешности в совмещении спутниковых данных разных съемочных аппаратов существенно ухудшают 
дешифровочные свойства синтезированного изображения. Тем не менее, в возникающих задачах длительного мониторинга растительного покрова не всегда представляется возможным использовать космическую съемку одного съемочного аппарата, что связано с ограниченным сроком эксплуатации спутников и съемочной аппаратуры. В большинстве случаев для исследований используются спутниковые данные, полученные различными съемочными системами. Поэтому для каждого изображения сначала проводится автоматизированная классификация, а дальнейший анализ динамики происходит на основе сравнения результатов дешифрирования.

Исследование базируется на данных экологического мониторинга, проведенных в НП «Куршская коса» в 1998-2007 гг. (Малышева и др., 2002; Князева, 2006).

Анализ и картографирование динамики растительного покрова НП «Куршская коса» проводились на основе результатов автоматизированного дешифрирования разновременных мультиспектральных космических снимков высокого пространственного разрешения - 10 м. Снимок 2007 года получен со спутника Alos, снимок 2017 года - co спутника Sentinel-2. Даты съемок выбраны ближе к середине вегетационного периода (июнь-июль). В качестве вспомогательных материалов при наборе эталонов для классификации также использовались комические снимки Sentinel-2 начала мая 2016 г. и середины января 2017 г. Космические снимки Sentinel-2 получены из базы EOBrowser открытого доступа (apps.sentinel-hub.com).

Выбор спутниковых данных для оценки динамики растительного покрова обусловлен близкими характеристиками пространственного и спектрального разрешения снимков, позволяющими получить оптимальные результаты классификации при заданных параметрах съемки (табл.1).

Таблица 1. Характеристика используемых для выявления динамики растительного покрова данных высокого пространственного разрешения

\begin{tabular}{|c|c|c|c|c|}
\hline Спутник & $\begin{array}{c}\text { Срок } \\
\text { эксплуатации }\end{array}$ & $\begin{array}{c}\text { Пространственное } \\
\text { разрешение, м }\end{array}$ & $\begin{array}{c}\text { Спектральный диапазон } \\
\text { каналов, мкм } \\
\end{array}$ & $\begin{array}{c}\text { Дата } \\
\text { съемки }\end{array}$ \\
\hline \multirow{3}{*}{$\begin{array}{c}\text { Alos } \\
\text { (Япония) }\end{array}$} & \multirow{3}{*}{$\begin{array}{c}24 \text { октября } 2006 \text { - } \\
22 \text { апреля } 2011\end{array}$} & \multirow[t]{3}{*}{$-c_{2}=$} & зеленый: $0.52-0.6$ & \multirow{3}{*}{$\begin{array}{c}11 \text { июня } \\
2007\end{array}$} \\
\hline & & & красный: $0.61-0.69$ & \\
\hline & & & $\begin{array}{c}\text { ближний ИК: } \\
0.76-0.89 \\
\end{array}$ & \\
\hline \multirow{3}{*}{$\begin{array}{l}\text { Sentinel- } \\
2 *(E C)\end{array}$} & \multirow{3}{*}{$\begin{array}{c}23 \text { июня } 2015- \\
\text { наст.вр. }\end{array}$} & \multirow{3}{*}{10} & зеленый: 0.54-0.58 & \multirow{3}{*}{$\begin{array}{c}20 \text { июля } \\
2017\end{array}$} \\
\hline & & & красный: $0.64-0.68$ & \\
\hline & & & ближний ИК: $0.78-0.9$ & \\
\hline
\end{tabular}

Материалы съемки имеют предварительную обработку уровня $1 \mathrm{C}$ с нулевой облачностью и представлены в проекции WGS 84 / UTM zone 34N. В программе ERDASImagine выполнен синтез зеленого, красного и ближнего ИК каналов изображений, как 
наиболее информативных для изучения растительного покрова, и вырезан фрагмент территории российской части Куршской косы.

Совмещение спутниковых и картографических данных лесоустройства проведено при помощи трансформирования многозональных изображений методом аффинных преобразований в программном комплексе ArcGIS (ошибка трансформирования не превышала 1-2 пиксела).

Для автоматизированной классификации в качестве данных для обучения и проверки точности классификации использованы таксационная база данных лесоустройства НП 2003 г. и данные полевых наземных обследований лесной растительности 2017 г. на территории НП.

Измерение биометрических параметров древостоев в рамках экспедиции 2017 г. проводилось методами глазомерно-инструментальной съемки на пробных площадях 50х50, 30х30, 20х20 м с составлением карт-схем размещения деревьев. Всего было заложено 15 ключевых участков в разных типах леса: 12 - в сосняках разного возраста (молодняки, средневозрастные и старовозрастные древостои), 1 - в березняке, 1 - в черноольшанике, 1 - в ельнике. Молодые сосняки представлены возрастным диапазоном до 40 лет, средневозрастные - от 41 до 80 лет, старовозрастные сосняки охватывают древостои приспевающей и спелой групп возраста от 81 до 140 лет.

Эталонные обучающие выборки для лесной растительности с использованием базы данных лесоустройства составлялись согласно следующим параметрам: доля преобладающей породы более 6 единиц в составе древостоя, полнота больше 0,6. Выборка древостоев по возрасту создавалась только для сосновых лесов, т. к. они представлены полным возрастным рядом и занимают значительные площади. Для остальных нелесных классов (луговая растительность, псаммофильная растительность, пески, водные объекты) эталоны создавались по результатам визуального дешифрирования снимков и полевым данным обследований территории парка. Выбирались однородные участки изображения внутри лесных таксационных выделов (группы выделов) или выбранных объектов. Для разновременных снимков выбирались одинаковые обучающие участки (не подверженные изменениям) за исключением корневой части Куршской косы (которую не охватывает снимок Alos) и класса «несомкнувшиеся культуры сосны» как наиболее динамичного объекта. При классификации сосновых лесов по возрастному критерию выбирались эталонные участки в середине возрастного диапазона. Репрезентативные наборы эталонов сформированы для 11 классов: водные объекты; открытые песчаные дюны и пляж; псаммофильная растительность на дюнах; луговая растительность; несомкнувшиеся культуры сосны; сосняки молодые (до 40 лет); сосняки средневозрастные (41 - 80 лет); сосняки старовозрастные (81 - 140 лет); еловые леса; мелколиственные леса (береза, осина); черноольховые леса. Всего было сформировано 255 
эталонных участков общей площадью 575 га (31699 samples) для снимка Alos и 270 участков, площадью 594 га (34418 samples) - для Sentinel-2 (2016 и 2017 г.).

В качестве методов классификации космических снимков Alos и Sentinel-2 выбраны методы максимального правдоподобия (maximum likelihood estimation) и «Случайный лес» (Random forest) (Breiman,2001). Классификация разновременных космических снимков проведена в свободной среде разработки программного обеспечения RStudio.

Классификация методом Random Forest осуществлялась путем построения 1000 деревьев на основе 3-х спектральных каналов космического снимка. Обучающая выборка разделялась на 2 группы: эталонные участки для обучения и контрольные участки для проверки. Используемый алгоритм позволяет оценить прогнозируемую точность определения классов, рассчитываемую на основе исходной обучающей выборки, а также выявлять наиболее важные из признаков, использованных при классификации. В нашем варианте попиксельной классификации наиболее информативными признаками признаны спектральные изображения, полученные в красном и ближнем ИК каналах съемки, что подтверждают и кривые спектральных образов, показывающие наибольшую разделимость эталонов в этих диапазонах.

Точность классификаций оценивалась по критерию каппа Коэна (Cohen, 1960). Результаты представлены в таблице 2. Классификация, проведенная методом «Случайный лес» (RandomForest), показала более точные результаты в сравнении с методом максимального правдоподобия. В связи с этим для дальнейшего анализа результатов был выбран метод RandomForest.

Таблица 2. Общая точность и коэффициент каппа для классификаций используемых спутниковых изображений

\begin{tabular}{|l|l|l|l|l|}
\hline \multicolumn{1}{|c|}{ Метод } & \multicolumn{2}{|c|}{ Максимального правдоподобия } & \multicolumn{2}{c|}{ Random Forest } \\
\hline $\begin{array}{l}\text { Космический } \\
\text { снимок }\end{array}$ & $\begin{array}{l}\text { Коэффициент } \\
\text { каппа }\end{array}$ & $\begin{array}{l}\text { Точность } \\
\text { (средняя) }\end{array}$ & $\begin{array}{l}\text { Коэффициент } \\
\text { каппа }\end{array}$ & $\begin{array}{l}\text { Точность } \\
\text { (средняя) }\end{array}$ \\
\hline ALOS & 0.8118 & 84.31 & 0.825 & 85.48 \\
\hline Sentinel-2 (2017 г.) & 0.7108 & 74.31 & 0.8055 & 83.75 \\
\hline
\end{tabular}

При анализе матрицы ошибок (перепутывания) определения тематических классов максимальная ошибка распознавания объектов на снимке Alos принадлежит классу «сосняк старовозрастный» и составляет 48\%. В основном перепутывание происходит между разными возрастными градациями сосняков. Небольшая часть участков старовозрастного сосняка распознается как березовые леса. Также происходит довольно существенная ошибка при распознании березовых древостоев (39\%), при этом большая часть ошибочно классифицированных березняков отнесена к черноольшаникам и, в меньшей степени, к соснякам. Общая точность классификации, представленная коэффициентом Каппа, достаточно высокая - 0.825. Максимальная ошибка при распознавании классов лесной 
растительности по данным Sentinel 2 соответствует классам «сосняк старовозрастный» (53\%) и «ельники» (68\%). Общая точность классификации равна 0.8.

Наиболее достоверно распознается по данным Alos и Sentinel класс «черноольшаники» - ошибка классификации не превышает 8\%. Максимальные ошибки классификации соответствуют классам «березняки», «ельники» и «сосняки» разных возрастных групп (преимущественно, старовозрастным). Леса с преобладанием ели и березы на территории Куршской косы более разнородны и мозаичны, чем сосновые и черноольховые леса. Черная ольха практически не создает на косе смешанных древостоев и представлена, в основном, насаждениями от 65 до 90 лет. Приуроченность черной ольхи к понижениям в рельефе и, как следствие, к избыточному увлажнению, а сосняков к возвышенным сухим местообитаниям, позволяют формировать более компактные однородные спектральные сигнатуры, чем для остальных классов. Поскольку наибольшее перепутывание классов сосняков происходит между возрастными градациями сосны целесообразно объединить эти классы между собой. Также представляется целесообразным объединить классы «псаммофильная растительность» и «несомкнувшиеся культуры сосны», т. к. оба класса относятся к не покрытым лесом землям, а эталонные участки не сомкнувшихся культур занимают слишком малую площадь по сравнению с другими классами. По этой же причине и ввиду того, что снимок Alos покрывает не всю территорию НП в отличие от снимка Sentinel, класс «ельники» объединен с классом «сосняки». Классификации растительности Куршской косы после объединения классов для снимков Alos и Sentinel представлены на рис. 1.

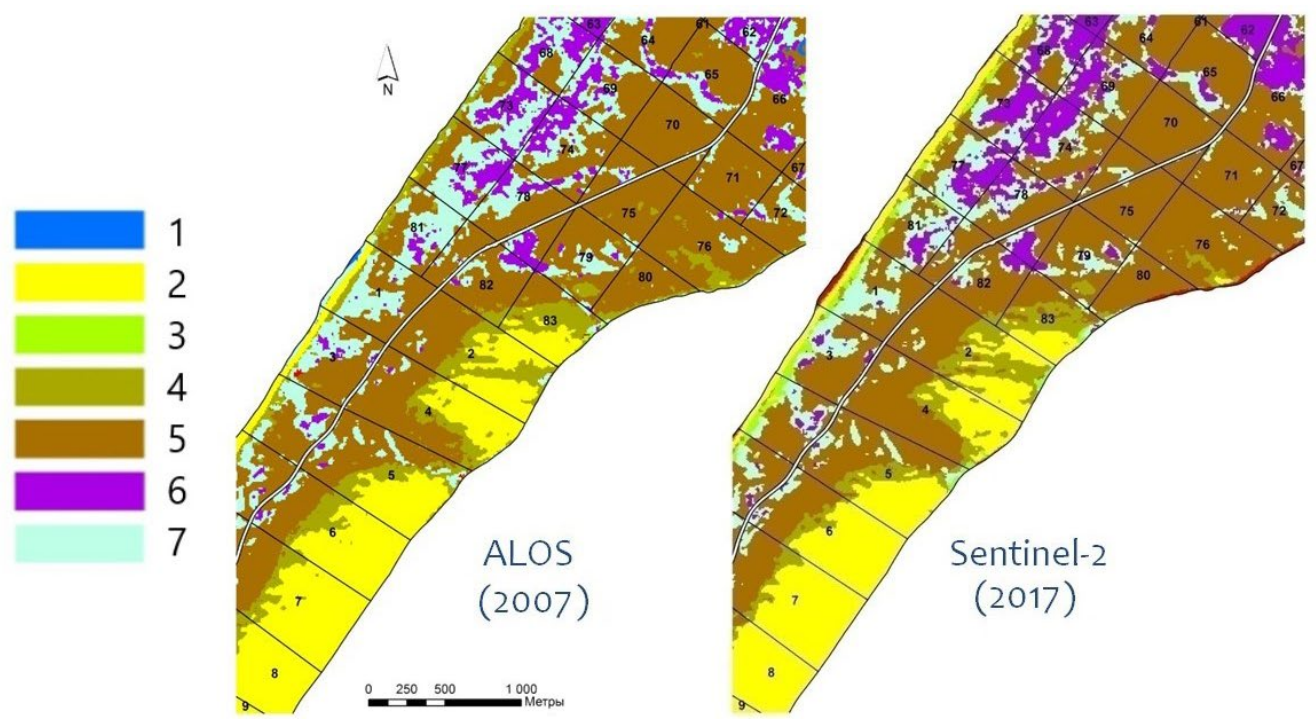

Рисунок 1. Результаты классификации растительности Куршской косы после объединения классов для снимков Alos и Sentinel; классы: 1 - водные объекты, 2 - песчаные дюны, пляж, 3 - луговая растительность, 4 - псаммофильная растительность, 5 - сосновые леса, 6 - черноольховые леса, 7 - березовые леса

Рубеж гарантированной воспроизводимости малых компактных объектов (без передачи их формы) при пиксельной генерализации составляет 4 пикселя (Кравцова, 2000). 
Для снижения фрагментарности изображений и исключения случайных классов (площадь

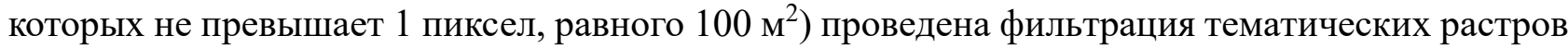
классификаций с использованием функции анализа окрестностей при выборе скользящего окна 3х3. Это позволяет количественно оценить изменения площадных характеристик растительного покрова Куршской косы за 10-летний период в границах квартальной сети с точностью не менее 0.1 га (9 пикселей).

В качестве показателей динамики для картографирования целесообразно использовать относительные площадные параметры, характеризующие устойчивость растительного покрова территории полуострова. Такие показатели были предложены группой ученых для организации и ведения экологического мониторинга дистанционными методами на особо охраняемых природных территориях (Малышева и др., 2002; Князева, 2006). Для Куршской косы предложено использовать лесистость (Л) территории (1) и долю хвойных пород (ДХ)(2) в древостое как универсальные показатели, а долю развеваемых песков (РП) (3) и долю песков, покрытых растительностью (3П) (4) как специальные показатели для данной территории.

$$
\begin{gathered}
\text { Л }=\frac{\sum S_{\text {лесных классов }}}{S_{\text {общ }}} * 100 \% \\
\text { ДХ }=\frac{\sum S_{\text {хвойных классов }}}{\sum S_{\text {лесных классов }}} * 100 \% \\
\text { РП }=\frac{S_{\text {песков }}}{S_{\text {общ }}} * 100 \% \\
\text { ЗП }=\frac{S_{\text {псаммофильной раст. }}+S_{\text {несомкнувшихся культур }}}{S_{\text {общ }}} * 100 \%
\end{gathered}
$$

Для расчета количественных значений показателей выбрана территориальная единица наблюдения в виде лесохозяйственного квартала. Расчет показателей динамики и составление карт выполнялись в программном комплексе ArcGIS c применением методов пространственного анализа (оверлей векторных слоев, расчет площадных характеристик) и геоинформационного картографирования. Вычисление разницы между значениями каждого показателя в 2017 и 2007 г. легло в основу составления карт динамики - лесистости, доли хвойных, доли развеваемых (открытых) песков и песков, покрытых растительностью (закрепленных песков).

По результатам автоматизированного дешифрирования космических снимков для НП «Куршская коса» составлена карта разновременного состояния растительности, отражающая изменения границ (контуров) растительных сообществ. Карта отображает совмещенные границы контуров классов в 2007 и 2017 гг. посредством способа качественного фона (цветом показаны типы растительных сообществ и природных объектов в 2007 г., а цветной штриховкой - в 2017 г.). 


\section{РЕЗУЛЬТАТЫ И ОБСУЖДЕНИЕ}

По результатам классификации разновременных космических снимков проанализирована структура классов растительных сообществ для лесничеств НП «Куршская коса» в 2007 и 2017 гг. Во всех случаях доля лесных насаждений превышает 68\%, с максимальным значением 72.2\% в 2017 г. В целом, для породной структуры характерно преобладание сосняков (более 40\%). Их доля слабо увеличивается к 2017 году (с 42 до 44\% в лесничестве «Золотые дюны» и с 43 до 48\% в Зеленоградском лесничестве). Доля березняков варьирует в пределах от 13 до 19\% и уменьшается к 2017 г. Наименьшая доля в структуре лесного покрова принадлежит черноольшаникам. Таким образом, общая структура лесного покрова территории НП за 10-летний период с 2007 по 2017 г. изменяется незначительно. При анализе показателей динамики, рассчитанных для лесничеств «Зеленоградское» и «Золотые дюны» можно сделать вывод об отсутствии значительных изменений на территории лесничеств в целом за период с 2007 по 2017 гг. (рис. 2). Изменение лесистости не превышает $3 \%$, развеваемых песков $-1 \%$.

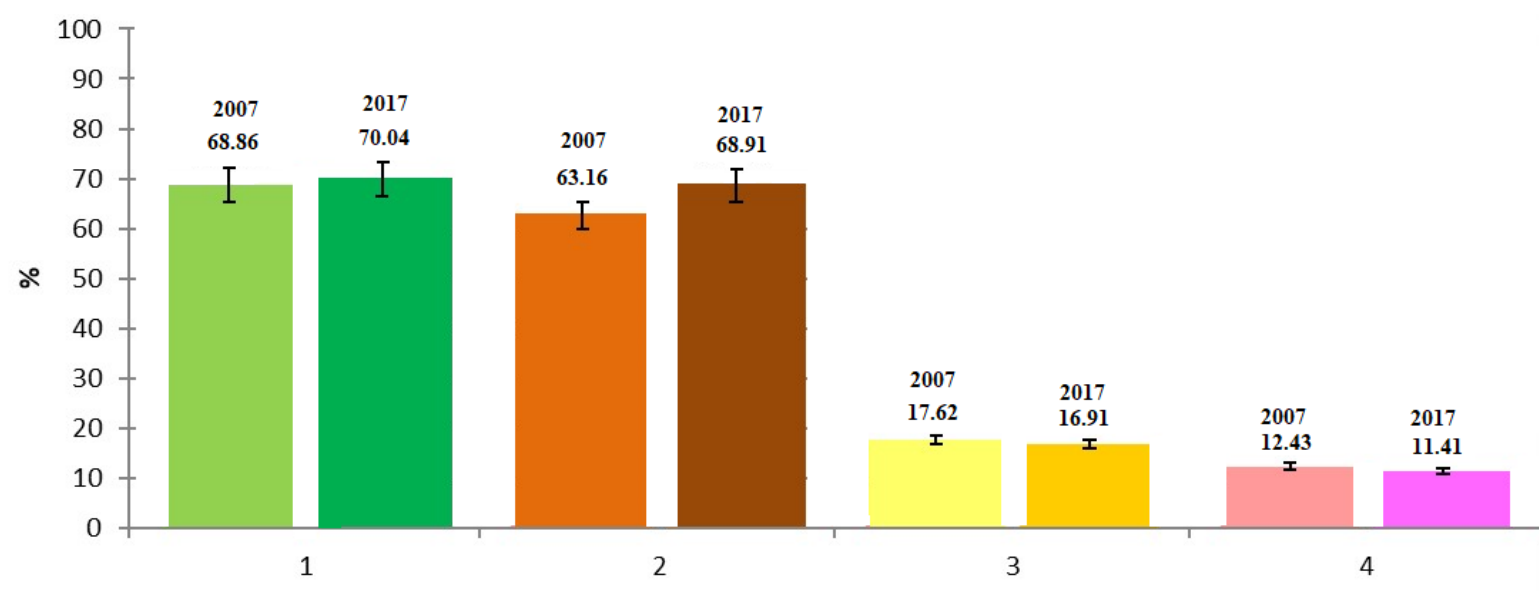

a)

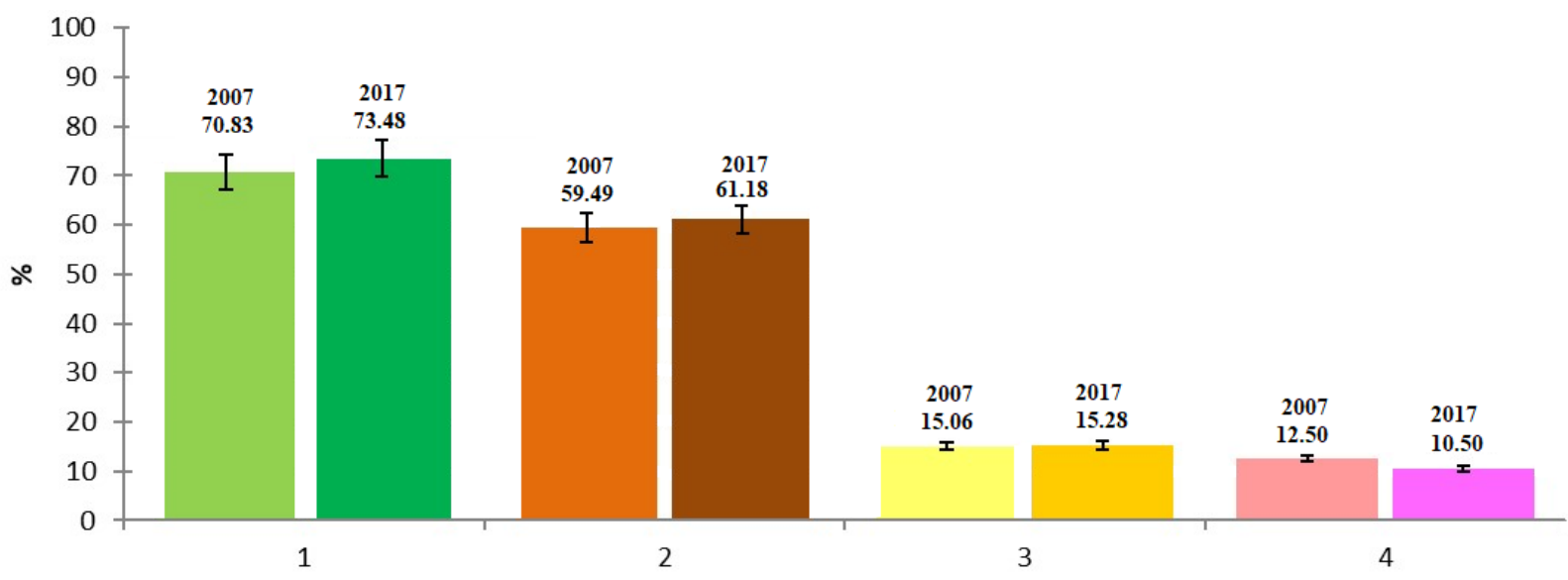

б)

Рисунок 2. Показатели динамики растительного покрова НП «Куршская коса» для лесничеств: а) Зеленоградское б) «Золотые дюны»: 1 - лесистость; 2 - доля хвойных; 3 - доля развеваемых песков; 4 - доля закрепленных песков 
Более детальную пространственную динамику показателей можно оценить при анализе значений для каждого квартала лесничеств. Изменение лесистости на территории НП варьирует в пределах от -18 до 30 \%. Следует отметить, что минимальные и максимальные значения представлены в единичных кварталах, а большая часть изменений находится в пределах от -9 до $10 \%$ (рис. 3).

\section{Изменение лесистости на территории национального парка "Куршская коса" в 2007-2017 гг.}

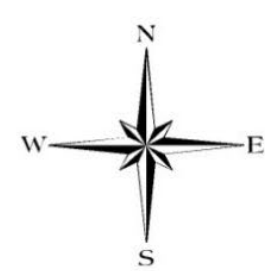

\section{Лесничество}

—— Золотые дюны

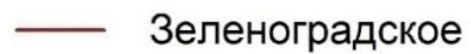

\section{Изменение лесистости, \%}

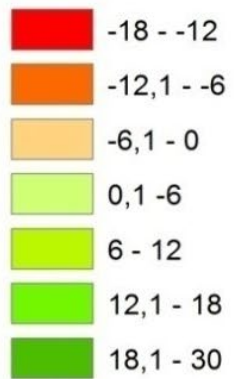

$1: 150000$

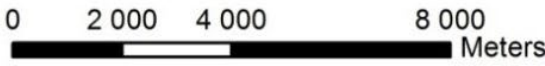

Рисунок 3. Карта изменения лесистости НП «Куршская коса» 
Максимальное увеличение лесистости наблюдается в 61 квартале лесничества «Золотые дюны» (29.5\%), где происходит зарастание сосняком участков ветровалов начала 2000-х гг. Также относительно большой рост лесистости отмечен для кварталов, приграничных с Литвой, за счет зарастания авандюны и закрепления песков псаммофильной растительностью.

Отрицательная динамика лесистости характерна для кварталов, приуроченных к морскому побережью, что обусловлено интенсивными эрозионными и абразионными процессами на береговой авандюне. Ежегодные шторма размывают пески, покрытые псаммофильной растительностью, а при сильных штормах нарушают и лесные сообщества. Максимальное снижение этого показателя отмечено в 43 квартале лесничества «Золотые дюны» (-17\%). Также стоит отметить, что часть выявленных изменений обусловлена ошибкой классификации, возникающей в результате высокой фрагментарности растительного покрова авандюны. которая не позволяет достоверно дешифрировать тип растительности на спутниковых данных используемого разрешения. В 13 квартале снижение лесистости на 12\% связано с пожаром в 2014 г., когда выгорели значительные площади сосновых насаждений около п. Морское (рис. 4). В настоящее время на месте горельника посажены культуры сосны.

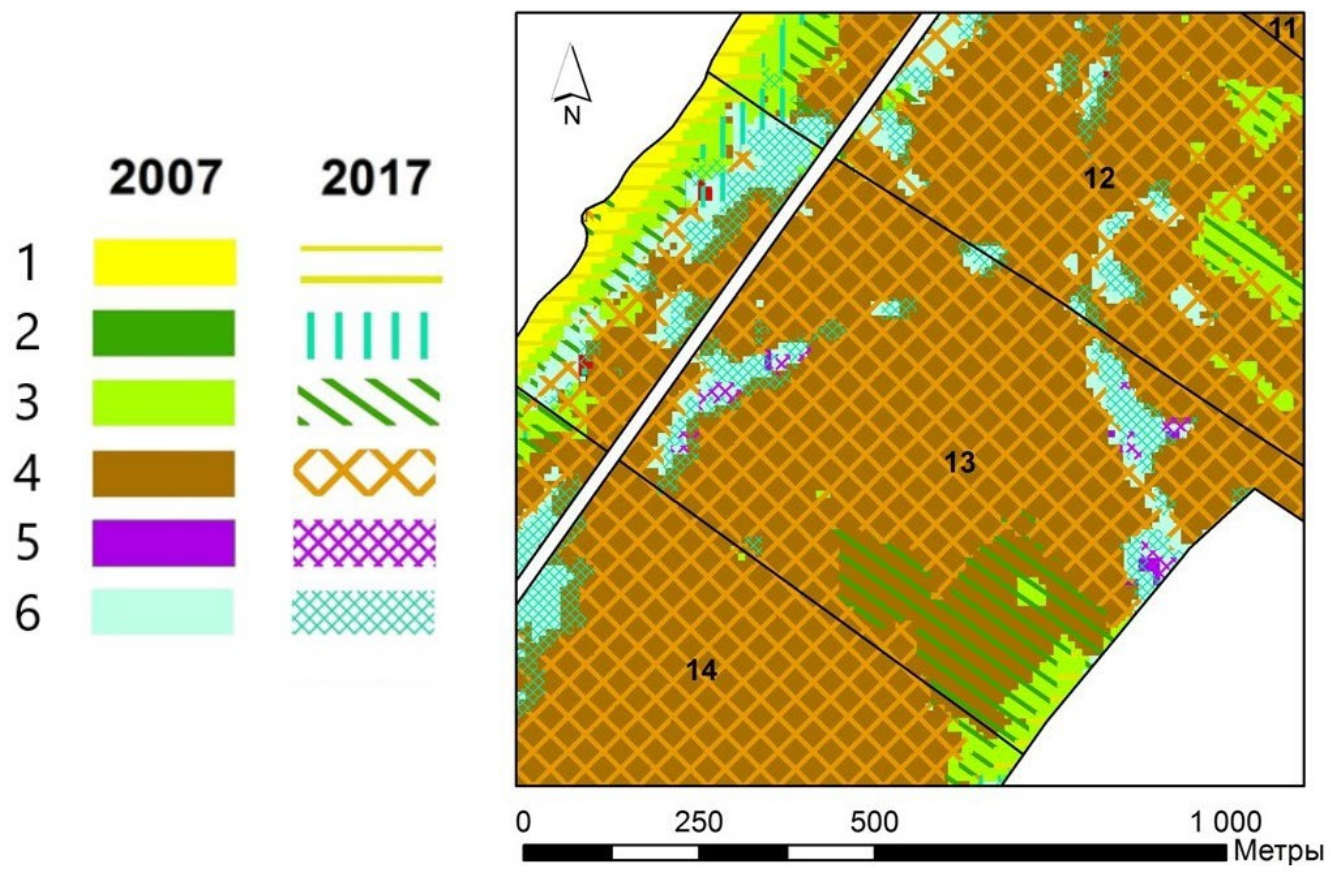

Рисунок 4. Фрагмент карты разновременного состояния растительности на территорию 13 квартала лесничества «Золотые дюны». Классы: 1 - песчаные дюны, пляж, 2 - луговая растительность, 3 - псаммофильная растительность, 4 - сосновые леса, 5 черноольховые леса, 6 - березовые леса

Динамика доли развеваемых песков отражает процессы закрепления движущихся песчаных дюн при помощи различных лесохозяйственных мероприятий - высадке растений- 
псаммофитов, посадке культур сосны. Доля развеваемых песков меняется от -13 до 11\% за десятилетний период (рис. 5).

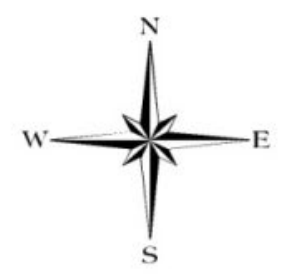

\section{Лесничество}

— Золотые дюны

— Зеленоградское

\section{Изменение доли развеваемых песков, \%}

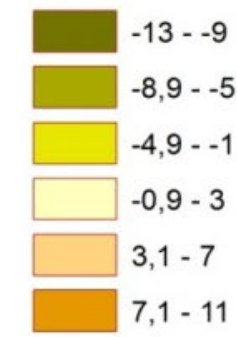

Рисунок 5. Карта динамики развеваемых песков НП «Куршская коса».

Наблюдается максимальное уменьшение доли развеваемых песков в 12 квартале (на $12.8 \%$ ) за счет закрепления песков псаммофильной растительностью (рис. 6). Также уменьшение незакрепленных песков фиксируется для кварталов, граничащих с Литвой. Увеличение доли развеваемых песков произошло в кварталах, приуроченных к морскому побережью. 


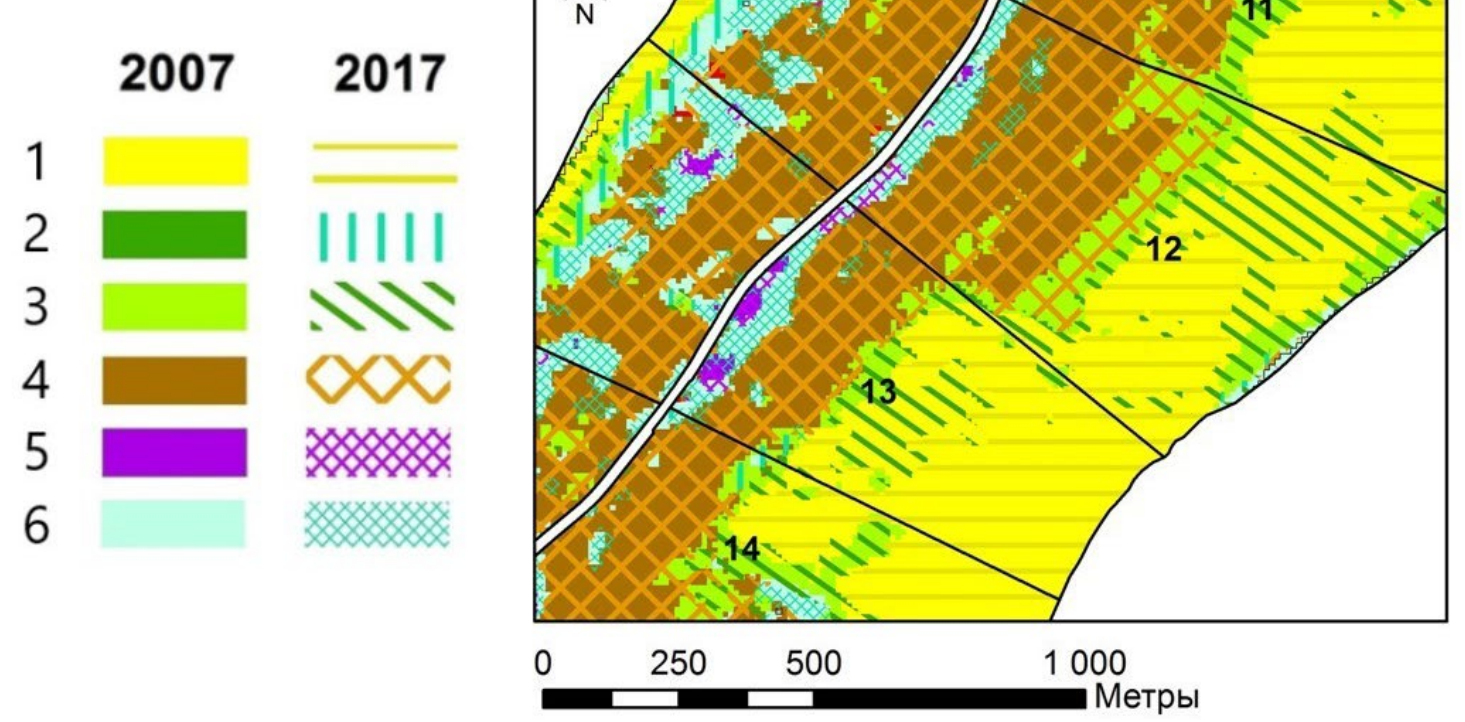

Рисунок 6. Фрагмент карты разновременного состояния растительности на территорию 12 и 13 кварталов Зеленоградского лесничества. Классы: 1 - песчаные дюны, пляж, 2 - луговая растительность, 3 - псаммофильная растительность, 4 - сосновые леса, 5 черноольховые леса, 6 - березовые леса

\section{ЗАКЛЮЧЕНИЕ}

В ходе исследования установлено, что спутниковые данные с разрешением 10 м обладают оптимальным сочетанием детальности и обзорности для дешифрирования основных типов растительности Куршской косы ввиду сложной вытянутой формы полуострова. Использование ДДЗ позволило выявить и количественно оценить изменения площадных характеристик растительного покрова территории НП «Куршская коса» за 10-летний период в границах квартальной сети с точностью не менее 0.1 га. Однако для участка берегового защитного вала, отличающегося сильной фрагментацией растительного покрова, требуется привлечение материалов съемки более высокого пространственного разрешения.

Сравнительный анализ работы алгоритмов классификации с обучением, методов максимального правдоподобия и RandomForest, показал, что оба алгоритма хорошо выявляют и оценивают характеристики растительности (коэффициент Каппа -0.78 и 0.8 соответственно). Однако RandomForest продемонстрировал более высокую достоверность распознавания основных природных объектов на территории Куршской косы (в частности, более высокие вероятности распознавания большинства классов лесной растительности). Также этот алгоритм предпочтительнее использовать ввиду гибкости настройки параметров классификации и менее строгих требований к репрезентативности обучающих эталонов в сравнении со статистическими классификаторами, к которым относится метод максимального правдоподобия. 
По результатам дешифрирования разновременных космических снимков получены новые данные об изменении площадных характеристик растительного покрова территории НП за период 2007 - 2017 гг. и составлены серии карт основных показателей динамики растительного покрова и карта разновременного состояния растительности. Максимальное снижение показателя лесистости (-17\%) отмечено на наиболее динамичном объекте НП авандюне, а максимальное увеличение (29\%) - на интенсивно зарастающих участках ветровалов 2000 г. Наибольшее уменьшение (-12\%) площадей развеваемых, не покрытых растительностью, песков происходит на территории НП, приграничной с Литвой, в результате мероприятий по закреплению движущихся песчаных дюн. В целом, при оценке изменения структуры растительного покрова НП прослеживаются следующие тренды: увеличения лесистости и доли закрепленных растительностью песков со стороны Куршского залива в результате лесозащитных мероприятий, уменьшение лесистости и увеличение доли развеваемых песков со стороны морского побережья в результате разрушения авандюны под воздействием ветро-волновой и рекреационной нагрузки.

\section{БЛАГОДАРНОСТИ}

Проведение полевых исследований и автоматизированное дешифрирование спутниковых данных выполнены при финансовой поддержке РФФИ (проект 17-05-01129 «Оценка биометрических и морфоструктурных параметров лесных фитоценозов на основе детальной аэрокосмической съемки»), картографическая оценка динамики растительного покрова Куршской косы выполнена в рамках государственного задания АAАA-А18118052400130-7 - «Методические подходы к оценке структурной организации и функционирования лесных экосистем».

Выражаем благодарность сотрудникам национального парка «Куршская коса» за помощь в организации и проведении полевых работ.

\section{СПИСОК ЛИТЕРАТУРЫ}

Гаврилюк Е.А., Ершов Д.В. Методика совместной обработки разносезонных изображений Landsat-TM и создания на их основе карты наземных экосистем Московской области // Современные проблемы дистанционного зондирования Земли из космоса. 2012. Т. 9. №. 4. C. 15-23.

Гранкина А.А., Мишвелов Е.Г. Состояние и динамика лесных фитоценозов особо охраняемых природных территорий Кавказских минеральных вод в условиях рекреационного воздействия // Наука. Инновации. Технологии. 2014. №. 4. С.121-129. 
Губарева И.Ю. Ботанические объекты // Особо ценные природные и культурные объекты национального парка «Куршская коса»: сб. науч. ст. / сост. О.В. Рыльков, И.П. Жуковская. Калининград: Изд-во РГУ им. И. Канта. 2009. С. 9-36.

Князева С.В. Картографо-аэрокосмический мониторинг лесов национальных парков: Дис. ... канд. геогр. наук. Москва, МГУ, 2006, 193 с.

Комарова А.Ф., Журавлева И.В., Яблоков В.М. Открытые мультиспектральные данные и основные методы дистанционного зондирования в изучении растительного покрова // Принципы экологии. 2016. №. 1 (17). С. 40-74.

Королева Н.В., Тихонова Е.В. Ершов Д.В., Салтыков А.Н., Гаврилюк Е.А., Пугачевский A.B. Оценка масштабов зарастания нелесных земель в национальном парке «Смоленское поозерье» за 25 лет по спутниковым данным Landsat // Лесоведение. 2018. №. 2. С. 83-96.

Кравцова В.И. Генерализация аэрокосмического изображения: континуальные и дискретные снимки. М.: Изд-во Моск. ун-та. 2000. С. 256.

Курбанов Э.А., Воробьев О.Н., Незамаев С.А., Губаев А.В., Лежнин С.А., Полевщикова Ю.А. Тематическое картирование и стратификация лесов Марийского Заволжья по спутниковым снимкам Landsat // Вестник Поволжского государственного технологического университета. Серия: Лес. Экология. Природопользование. 2013. №. 3 (19) С. 82-92.

Лабутина И.А., Балдина Е.А. Использование данных дистанционного зондирования для мониторинга экосистем ООПТ // М.: WWF России. 2011. С. 88.

Мальшева Н.В., Орлова О.Л., Князева С.В., Золина Т.А., Вуколова И.А. Мониторинг лесных экосистем национальных парков с использованием дистанционных методов и ГИСтехнологий. Методические подходы и опыт работ // Лесохозяйственная информация. 2002. № 12. C. $19-24$.

Национальный парк «Куршская коса»: официальный сайт. URL: http://www.parkkosa.ru (дата обращения 27 июня 2019).

Рассказов А.А., Галаганова Л.А. Использование данных LANDSAT для оценки динамики изменений растительного покрова на территории Мещеры // Научные труды Института непрерывного профессионального образования. 2014. №. 3. С. 236.

Рязанов С.С., Сахабиев И.А., Галимов Д.З. Классификация земного покрова островов Куйбышевского водохранилища с использованием данных дистанционного зондирования // Российский журнал прикладной экологии. 2015. №. 3 (3). С. 50-55.

Сухих В.И., Жирин В.M. Применение сканерных космических снимков при инвентаризации резервных лесов // Дистанционные методы в лесоустройстве и учете лесов. Приборы и технологии: Материалы Всероссийского совещания-семинара с международным участием. Красноярск: Институт леса им. ВН Сукачева СО РАН. 2005. С. 92. 
Тютрин С.А., Кондратовеи Р.Б. Дистанционный мониторинг незаконных рубок в Дальневосточном федеральном округе // Земля из космоса: наиболее эффективные решения. 2010. №. 4. C. 73-76

Чебакова И.В. Национальные парки России. М.: Изд-во Центра охраны дикой природы. 1996. C. 198.

Шапльгина T.В., Волкова И.И. Геоэкологические аспекты рекреационного природопользования в национальном парке «Куршская коса» Сб. материалов всероссийской научно-практической конференции «Проблемы природопользования, сохранения биоразнообразия и культурного наследия на особо охраняемых природных территориях России», Калининград, Изд-во БФУ им. Им. И. Канта. 2017. С. 128-134.

Ялдыгина Н.Б. Использование программного комплекса ENVI для решения задач лесного хозяйства // Геоматика. 2011. №. 3. С. 34-39.

Banskota A., Kayastha N., Falkowski M., Wulder M.A., Froese R.E., White J.C. Forest monitoring using Landsat time-series data: A review // Canadian Journal of Remote Sensing. 2014. Vol. 40. No. 5. P. 362-384.

Boisvenue C., Smiley B.P., White J.C., Kurz W.A., Wulder M.A. Integration of Landsat time series and field plots for forest productivity estimates in decision support models // Forest Ecology and Management. 2016. T. 376. C. 284-297.

Breiman L. Random forests // Machine learning. 2001. Vol. 45. No. 1. P. 5-32.

Chen Y., Dengsheng L., Geping L., Jingfeng H. Detection of vegetation abundance change in the alpine tree line using multitemporal Landsat Thematic Mapper imagery // International Journal of Remote Sensing. 2015. Vol. 36. No. 18. P. 4683-4701.

Cohen J.A coefficient of agreement for nominal scales // Educational and Psychological Measurement. 1960. Vol. 20. No 1. P. 37-46.

EO Browser URL: https://apps.sentinel-hub.com/eo-browser (дата обращения 27 июня 2019).

Gavier-Pizarro G.I., Kuemmerle T., Hoyos L.E., Stewart S.I., Huebner C.D., Keuler N.S., Radeloff V.C. Monitoring the invasion of an exotic tree (Ligustrum lucidum) from 1983 to 2006 with Landsat TM/ETM+ satellite data and Support Vector Machines in Córdoba, Argentina // Remote Sensing of Environment. 2012. Vol. 122. P. 134-145.

Gould W. Remote sensing of vegetation, plant species richness, and regional biodiversity hotspots // Ecological applications. 2000. Vol. 10. No. 6. P. 1861-1870.

Hansen M.C., Potapov P.V., Moore R., Hancher M., Turubanova S.A., Tyukavina A. et al. High-resolution global maps of 21st-century forest cover change // Science. № 342(6160). P. 850853. 
Homolova L., Malenovský Z., Clevers J.G., Garcia-Santos G., Schaepman M.E. Review of optical-based remote sensing for plant trait mapping // Ecological Complexity. 2013. Vol. 15. P. 116.

Immitzer M., Vuolo F., Atzberger C. First experience with Sentinel-2 data for crop and trees species classifications in central Europe // Remote Sensing. 2016. Vol. 8. No. 3. P. 166

McRoberts R.E., Cohen W.B., Ncesset E., Stehman S.V., Tomppo E.O. Using remotely sensed data to construct and assess forest attribute maps and related spatial products // Scandinavian Journal of Forest Research. 2010. Vol. 25. No. 4. P. 340-367.

Nagendra H., Lucas R., Honrado J.P., Jongman R.H., Tarantino C., Adamo M., Mairota P. Remote sensing for conservation monitoring: Assessing protected areas, habitat extent, habitat condition, species diversity, and threats // Ecological Indicators. 2013. Vol. 33. P. 45-59.

Turner W., Rondinini C., Pettorelli N., Mora B., Leidner A. K., Szantoi Z., Buchanan G., Dech S., Dwyer J., Herold M., Koh L.P., Leimgruber P., Taubenboeck H., Wegmann M., Wikelski M., Woodcock C. Free and open-access satellite data are key to biodiversity conservation // Biological Conservation. 2015. Vol. 182. P. 173-176.

Xie Y., Sha Z., Yu M. Remote sensing imagery in vegetation mapping: a review // Journal of plant ecology. 2008. Vol. 1. No. 1. P. 9-23.

\section{REFERENCES}

Banskota A., Kayastha N., Falkowski M., Wulder M.A., Froese R.E., White J.C., Forest monitoring using Landsat time-series data: A review, Canadian Journal of Remote Sensing, 2014, Tom 40, No. 5. pp. 362-384.

Boisvenue C., Smiley B.P., White J.C., Kurz W.A., Wulder M.A., Integration of Landsat time series and field plots for forest productivity estimates in decision support models, Forest Ecology and Management, 2016, Tom 376, pp. 284-297.

Breiman L., Random forests, Machine learning, 2001, Tom 45. No. 1. pp. 5-32.

Chebakova I.V., Nacional'nye parki Rossii, Moscow: Izd-vo Centra ohrany dikoj prirody, 1996, p. 198.

Chen Y., Dengsheng L., Geping L., Jingfeng H., Detection of vegetation abundance change in the alpine tree line using multitemporal Landsat Thematic Mapper imagery, International Journal of Remote Sensing, 2015, Tom 36, No.18, pp. 4683-4701.

Cohen J., A coefficient of agreement for nominal scales, Educational and Psychological Measurement, 1960, Vol. 20, No.1, pp. 37-46.

Gavier-Pizarro G.I., Kuemmerle T., Hoyos L.E., Stewart S.I., Huebner C.D., Keuler N.S., Radeloff V.C., Monitoring the invasion of an exotic tree (Ligustrum lucidum) from 1983 to 2006 
with Landsat TM/ETM+ satellite data and Support Vector Machines in Córdoba, Argentina, Remote Sensing of Environment, 2012, Vol. 122, pp. 134-145.

Gavrilyuk E.A., Ershov D.V., Metodika sovmestnoj obrabotki raznosezonnyh izobrazhenij Landsat-TM i sozdaniya na ih osnove karty nazemnyh ekosistem Moskovskoj oblasti (Methods of joint processing of Landsat-TM multi-season images and creating on their basis maps of terrestrial ecosystems of the Moscow Region), Sovremennye problemy distancionnogo zondirovaniya Zemli iz kosmosa, 2012, Tom. 9, No. 4, pp. 15-23.

Gould W., Remote sensing of vegetation, plant species richness, and regional biodiversity hotspots, Ecological applications, 2000, Vol. 10, No. 6, pp. 1861-1870.

Grankina A.A., Mishvelov E.G., Sostoyanie i dinamika lesnyh fitocenozov osobo ohranyaemyh prirodnyh territorij Kavkazskih mineral'nyh vod $\mathrm{v}$ usloviyah rekreacionnogo vozdejstviya (State and dynamics of forest phytocenoses of Caucasian mineral waters specially protected natural territories under the conditions of recreational impact), Nauka. Innovacii. Tekhnologii, 2014, No. 4, pp. 121-129.

Gubareva I.Yu. Botanicheskie ob"ekty (Botanical objects). Osobo cennye prirodnye $i$ kul'turnye ob"ekty nacional'nogo parka «Kurshskaya kosa»: sb. nauch. st. sost. O.V. Ryl'kov, I.P.ZHukovskaya (Especially Valuable Natural and Cultural Objects of the Curonian Spit National Park: Coll. of Sc. Art.,Comp. O.V. Rylkov, I.P. ZHukovskaya), Kaliningrad, Izd-vo RGU im. I. Kanta, 2009, pp. 9-36.

Hansen M.C., Potapov P.V., Moore R., Hancher M., Turubanova S.A., Tyukavina A. et al., High-resolution global maps of 21st-century forest cover change, Science, No. 342 (6160), pp. 850853.

Homolova L., Malenovsky Z., Clevers J.G., Garcia-Santos G., Schaepman M.E., Review of optical-based remote sensing for plant trait mapping, Ecological Complexity, 2013, Vol. 15, pp. 116.

http://www.park-kosa.ru $(2019,27$ June).

https://apps.sentinel-hub.com/eo-browser $(2019,27$ June).

Immitzer M., Vuolo F., Atzberger C. First experience with Sentinel-2 data for crop and trees species classifications in central Europe, RemoteSensing, 2016, Vol. 8, No. 3, p. 166

Knyazeva S.V., Kartografo-aehrokosmicheskij monitoring lesov nacional'nyh parkov: Dis.kand.geogr.nauk (Cartographic-aerospace monitoring of national parks forests: the dissertation of the geographical sciences candidate), Moscow, MSU, 2006.

Komarova A.F., Zhuravleva I.V., YAblokov V.M., Otkrytye mul'tispektral'nye dannye i osnovnye metody distancionnogo zondirovaniya $\mathrm{v}$ izuchenii rastitel'nogo pokrova (Open 
multispectral data and main methods of remote sensing in the study of vegetation), Principy ekologii, 2016, No. 1 (17), pp. 40-74.

Koroleva N.V., Tihonova E.V. Ershov D.V., Saltykov A.N., Gavrilyuk E.A., Pugachevskij A.V., Ocenka masshtabov zarastaniya nelesnyh zemel' v nacional'nom parke "Smolenskoe poozer'e" za 25 let po sputnikovym dannym Landsat (Assessment of the extent of non-forest lands growing in the Smolensk Lakeland National Park for 25 years using satellite data Landsat), Lesovedenie, 2018, No. 2, pp. 83-96.

Kravcova V.I., Generalizaciya aehrokosmicheskogo izobrazheniya: kontinual'nye $i$ diskretnye snimki (Aerospace Image Generalization: Continuous and Discrete Images), Moscow, Izdvo Mosk. un-ta, 2000, 256 p.

Kurbanov E.A., Vorob'ev O.N., Nezamaev, S.A., Gubaev A.V., Lezhnin S.A., Polevshchikova Yu.A., Tematicheskoe kartirovanie i stratifikaciya lesov Marijskogo Zavolzh'ya po sputnikovym snimkam Landsat (Thematic mapping and stratification of Mari Trans-Volga forests using Landsat satellite imagery), Vestnik Povolzhskogo gosudarstvennogo tekhnologicheskogo universiteta. Seriya: Les. Ekologiya. Prirodopol'zovanie, 2013, No. 3 (19), pp. 82-92.

Labutina I.A., Baldina E.A., Ispol'zovanie dannyh distancionnogo zondirovaniya dlya monitoringa ekosistem OOPT (Use of remote sensing data for monitoring ecosystems of protected areas), Moscow: WWF Rossii, 2011, p. 88.

Malysheva N.V., Orlova O.L., Knyazeva S.V., Zolina T.A., Vukolova I.A., Monitoring lesnyh ehkosistem nacional'nyh parkov $\mathrm{s}$ ispol'zovaniem distancionnyh metodov i GIS-tekhnologij. Metodicheskie podhody i opyt rabot (Monitoring forest ecosystems of national parks using remote sensing methods and GIS technologies. Methodical approaches and work experience), Lesohozyajstvennaya informaciya, 2002, No. 12, pp. 19-24.

McRoberts R.E., Cohen W.B., Næsset E., Stehman S.V., Tomppo E.O. Using remotely sensed data to construct and assess forest attribute maps and related spatial products, Scandinavian Journal of Forest Research, 2010, Vol. 25, No. 4. pp. 340-367.

Nagendra H., Lucas R., Honrado J.P., Jongman R.H., Tarantino C., Adamo M., Mairota P. Remote sensing for conservation monitoring: Assessing protected areas, habitat extent, habitat condition, species diversity, and threats, Ecological Indicators, 2013, Vol. 33, pp. 45-59.

Rasskazov A.A., Galaganova L.A., Ispol'zovanie dannyh LANDSAT dlya ocenki dinamiki izmenenij rastitel'nogo pokrova na territorii Meshchery (Use of LANDSAT data to assess changes in vegetation cover in Meshchera), Nauchnye trudy Instituta nepreryvnogo professional'nogo obrazovaniya, 2014, No. 3, p. 236.

Ryazanov S.S., Sahabiev I.A., Galimov D.Z., Klassifikaciya zemnogo pokrova ostrovov Kujbyshevskogo vodohranilishcha $\mathrm{s}$ ispol'zovaniem dannyh distancionnogo zondirovaniya 
(Classification of the land cover of the islands of the Kuibyshev reservoir using remote sensing data), Rossijskij zhurnal prikladnoj ekologii, 2015, No. 3 (3), pp.50-55.

Shaplygina T.V., Volkova I.I., Geoehkologicheskie aspekty rekreacionnogo prirodopol'zovaniya v nacional'nom parke "Kurshskaya kosa” (Geoecological aspects of recreational environmental management in the Curonian Spit National Park). Sb. materialov vserossijskoj nauchno-prakticheskoj konferencii "Problemy prirodopol'zovaniya, sohraneniya bioraznoobraziya $i$ kul'turnogo naslediya na osobo ohranyaemyh prirodnyh territoriyah Rossii" (Materials Collection of the Russian Scientific-Practical Conference "Problems of Nature Management, Biodiversity Conservation and Cultural Heritage in Specially Protected Natural Areas of Russia"), Kaliningrad, Izd-vo BFU im. Im. I. Kanta, 2017, pp. 128-134.

Suhih V.I., Zhirin V.M., Primenenie skanernyh kosmicheskih snimkov pri inventarizacii rezervnyh lesov (The use of scanner satellite images in the inventory of reserve forests), Distancionnye metody v lesoustrojstve i uchete lesov. Pribory i tekhnologii: Materialy Vserossijskogo soveshchaniya-seminara s mezhdunarodnym uchastiem (Remote Methods in Forest Management and Forest Accounting. Instruments and Technologies: Materials of the All-russian Meeting-Seminar with International Participation.), Krasnoyarsk: Institut lesa im. V.N. Sukacheva SO RAS, 2005, p. 92.

Turner W., Rondinini C., Pettorelli N., Mora B., Leidner A.K., Szantoi Z., Buchanan G., Dech S., Dwyer J., Herold M., Koh L.P., Leimgruber P., Taubenboeck H., Wegmann M., Wikelski M., Woodcock C., Free and open-access satellite data are key to biodiversity conservation, Biological Conservation, 2015, Vol. 182, pp. 173-176.

Tyutrin S.A., Kondratovec R.B., Distancionnyj monitoring nezakonnyh rubok v Dal'nevostochnom federal'nom okruge (Remote monitoring of illegal logging in the Far Eastern Federal District), Zemlya iz kosmosa: naibolee ehffektivnye resheniya. 2010, No. 4, pp. 73-76.

Xie Y., Sha Z., Yu M., Remote sensing imagery in vegetation mapping: a review, Journal of plant ecology, 2008, Vol. 1, No. 1. pp. 9-23.

Yaldygina N.B., Ispol'zovanie programmnogo kompleksa ENVI dlya resheniya zadach lesnogo hozyajstva (Using the ENVI software package for solving forestry problems), Geomatika, 2011, No. 3, pp. 34-39. 


\title{
VEGETATION COVER DYNAMICS MAPPING OF THE CURONIAN SPIT NATIONAL PARK USINGSATELLITE IMAGERY ALOS AND SENTINEL-2
}

\author{
A.D. Nikitina*, S.V. Knyazeva, E.A. Gavrilyuk, \\ E.V. Tikhonova, S.P. Eydlina, N.V. Koroleva \\ Center for Forest Ecology and Productivity of the RAS \\ Profsoyuznaya st. 84/32 bldg. 14, Moscow, 117997, Russia \\ *E-mail: nikitina.al.dm@gmail.com \\ Received 24 June 2019
}

This article presents the results of assessing the quantitative changes in the area characteristics of the vegetation cover of the Curonian Spit National Park using materials from different-time multispectral imaging from satellite devices Alos and Sentinel-2 of high spatial resolution. Algorithms of automated classification "Random Forest" and "Maximum Likelihood Method" (Maximum Likelihood Estimation) were tested. Based on the obtained data of automated decoding of satellite images, indicators ecosystems monitoring of the national park were calculated, maps of the dynamics of these indicators and a map of different-time state of vegetation were compiled. The results show the direction of changes in the vegetation of the Curonian Spit over the ten-year period from 2007 to 2017: an increase in the proportion of forests and the proportion of sands fixed by vegetation near the Curonian Lagoon as a result of forest protection measures, a decrease in the proportion of forests and an increase in the proportion of waving sands near the sea coast as a result of the destruction of foredune under the influence of wind, wave and recreational loads.

Key words: vegetation cover, forest types, high spatial resolution satellite data, classification of satellite images, automated interpretation, recognition accuracy, indicators of environmental monitoring, dynamics maps

Рецензент: к.г.н., доцент Малышева Н.В. 